\title{
COGNITIVE FUNCTIONS AND STRUCTURE OF DISORDERS IN PATIENTS WITH HYPERTENSION
}

\author{
Viktoriia Krotova ${ }^{1 *}$
}

Author information: ${ }^{1}$ Dnipropetrovsk Medical Academy of the Ministry of Health of Ukraine, 9, V. Vernadsky str, Dnipro, Ukraine

\begin{abstract}
Age, heredity, and cardiovascular disease, especially arterial hypertension, are important risk factors for cognitive impairment $(\mathrm{Cl})$. The aim of the study is to determine the features of the development and structure of cognitive impairment in patients with controlled stage II arterial hypertension using a battery of neuropsychological tests. The main group of the study consisted of 157 patients with hypertension and mean age of $52.3 \pm 0.68$ years. According to the MoCA test in patients with hypertension, there was a decrease in scores on all subscales compared to healthy controls, but the largest deviations (over $20 \%$ of the maximum score) were observed in the ability to perform serial subtraction (35.0\%), delayed recall (27.0\%), abstraction (24.0\%), and in visual-constructive / executive skills $(21.0 \%)$. All patients with hypertension with detected $\mathrm{Cl}$ had deviations of concentration in the excitatory process of the visual and motor analyzers. Thus, only 2 patients (1.3\%) performed tasks without errors in either of the 5 sectors (normal), up to 4 sectors coped with counting 28 patients ( $17.8 \%$ ), up to 3 sectors -65 patients ( $41.4 \%)$, up to 2 sectors -56 patients( $35.7 \%)$, another 6 patients (3.8\%) aged 55 to 65 years could not complete the task without errors - by method F.E. Rybakov. The level of attention and speed of sensory-motor reactions was carried out according to the method of "Schulte Tables". Patients were characterized by rapid fatigue, uneven performance of the task, and refusal to perform further due to fatigue and inability to concentrate. The average time of the task in patients of the main group throughout the study exceeded the data of patients in the comparison group by 1.3-1.6 times, and healthy individuals by 1.4-1.7 times. Patients with hypertension have disorders at different levels of higher brain functions that correspond to all areas of human cognitive activity, but the most affected are neurodynamic processes (the ability to concentrate, the speed of psychomotor reactions) and verbal memory, which affect efficiency and success in work, which is important for medical rehabilitation and maintaining the mental health of patients.
\end{abstract}

Keywords: Mental health, Arterial hypertension, Cognitive impairment, Neuropsychological tests

INTRODUCTION Mental health is a priority for the quality of human life. It is urgent to pay attention to the state of cognitive functions in medical rehabilitation. In addition to age and heredity, cardiovascular disease, especially arterial hypertension (AH), is an important risk factor for cognitive impairments $(\mathrm{Cl})$. With hypertension, the risk of developing vascular dementia is $62 \%$ higher between the ages of 30-50 years [1].The relationship between blood pressure (BP) and the state of cognitive functions (CF) has been found in large epidemiological studies (Framingham, EVA Gothenburg, Honolulu-Asia Aging Study, Systolic

*Corresponding author: Viktoriia Krotova, Dnipropetrovsk Medical Academy of the Ministry of Health of Ukraine ,9, V. Vernadskystr, Dnipro, Ukraine, vika_krotova@ukr.net

Viktoriia Krotova (C
Hypertension in Europe trials, PROGRESS, LIFE, SCOPE, MOSES, ONTARGET, TRANSCEND). Results from neuropsychological tests showed a significant negative feedback between blood pressure levels, duration of hypertension, and visual and auditory memory. The findings of large-scale international clinical studies [2] indicated that age, hypertension, multifocal atherosclerosis, and CF are interrelated and affect the level of patient disability, quality of life, and social adaptation. Cognitive impairment was found in $73 \%$ of middle-aged and elderly patients who had hypertension over 5 years [3-5]. One year later, $5-15 \%$ of patients with moderate $\mathrm{Cl}$ developed dementia. Importantly, in $25-30 \%$ of patients, reversal of symptoms is possible, which is encouraging [6]. 
The aim of the study was to determine the features of development and structure of cognitive impairments of patients with controlled hypertension stage II using a battery of neuropsychological tests.

\section{MATERIAL AND METHODS}

\section{Study Group}

Five hundred nine patients with controlled stage II hypertension (target blood pressure levels $<140 / 90 \mathrm{~mm}$ $\mathrm{Hg}$ ) were examined in the clinic. The mean age of the subjects was $52.3 \pm 0.68$ years. $55.4 \%$ of patients were women and $44.6 \%$ men. Based on the data of neuropsychological testing from a cohort of examined patients, 164 people with cognitive impairment were identified. Of these, the main group of the study consisted of 157 patients with stage II hypertension, according to the criteria of inclusion - non-dementia $\mathrm{Cl}$, no signs of depression. All patients were low cardiovascular risk (CVR) on the SCORE scale (up to 5\%). The comparison group consisted of 28 patients with controlled stage II hypertension, without $\mathrm{Cl}$. To determine the reference values of psychophysiological indicators in the adult population of the Dnipro region of Ukraine, a sample of 28 age-matched healthy working women and men (without hypertension and cognitive impairment) with similar education levels as the main group were enrolled.

In-depth neuropsychological research was performed using an array of standardized neuropsychological tests: MMSE (Mini-Mental State Examination) and MoCA (Montreal Cognitive Assessment) scales for integrated assessment of CF [7-9], as well as their individual components; frontal dysfunction scale FAB [10], (Frontal
Assessment Battery); O. Luria's method for studying the state of verbal memory [11]; Schulte's technique for assessing the attention and speed of sensorimotor reactions [10]; F.E. Rybakova's method for the study of attention $[9,10]$.

\section{Statistical Analysis}

Statistical processing of the results was performed using the licensed package of statistical analysis software STATISTICA version 6.1 (StatsoftInc., USA), serial number AGAR909E415822FA. Under the normal distribution law, parametric characteristics and methods of analysis were used: arithmetic mean (M), standard error $(m)$, standard deviation (SD), 95\% confidence interval for the mean $(95$ $\% \mathrm{Cl}$ ). The critical value of the indicator (demarcation point), which provides the optimal operational characteristics of this criterion for prognosis (sensitivity, specificity), was determined using ROC-analysis (Receiver Operating Characteristic curve analysis). The area under the ROC curve (AUC - Area under the ROC curve) and its $95 \% \mathrm{Cl}$ were calculated. The critical level of statistical significance in testing all hypotheses was $<5 \%(p<0.05)$ [12].

RESULTS A retrospective analysis of the medical records of patients with hypertension in real outpatient medical practices showed the absence of any information on $\mathrm{Cl}$ during dispensary monitoring of the disease. The medical generalization regarding cognitive disorders was hidden and was regarded as "dyscirculatory encephalopathy". Targeted medical correction of $\mathrm{Cl}$ was not envisaged at all. It was found that primary care physicians did not have official regulatory documents, were not familiar with

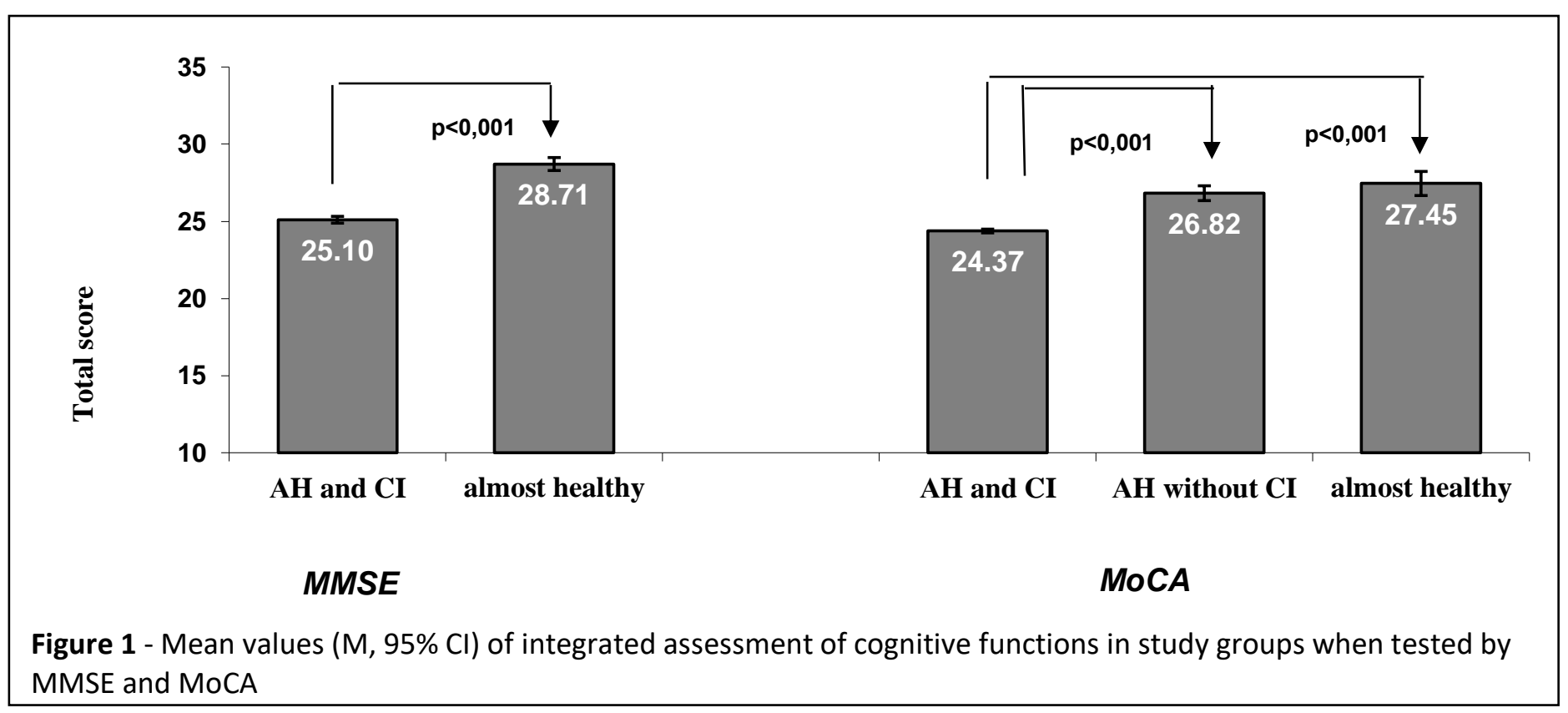


and/or had no experience in the diagnosis of $\mathrm{Cl}$, and were not experienced in planning primary prevention, secondary prevention, and treatment.

After a comprehensive neuropsychological study of 509 patients with controlled stage II hypertension, 164 patients were diagnosed with $\mathrm{Cl}(32.22 \%)$ with only $14 \%$ having complaints of memory impairment or impaired attention, which were not considered significant. Of the 97 patients in the main study group, the MMSE method in 39 patients ( $40.2 \%$ ) found mild $\mathrm{Cl}$ (27-26 points) and found moderate $\mathrm{Cl}$ (25-24 points) in 58 patients (59.8\%) The average severity of CF disorders in patients with hypertension was $25.10 \pm 0.11$, which was $12.6 \%$ less than healthy individuals $(28.71 \pm 0.21$ points) (Fig. 1). The integrated assessment of $\mathrm{CF}$ in the testing of patients with hypertension $(n=60)$ by the MoCA method was also low (24.37 \pm 0.06 points) and met the criteria of $\mathrm{Cl}$ (less than 26 points). the largest deviations (over $20 \%$ of the maximum score) were observed in the ability to perform serial subtraction $(35.0 \%)$, delayed recall $(27,0 \%)$, abstraction (by $24.0 \%)$, and in visual-constructive / executive skills (by $21.0 \%$ ).

When conducting a study using frontal dementia FAB among 97 patients of the main group (hypertension with $\mathrm{Cl}$ ), no cases resulted in diagnostically low values (less than 12 points), which indicates a pronounced frontal dysfunction. Sixty-one patients (62.9\%) had normal frontal function scores (16-18 points). The other 36 patients (37.1\%) received 15 points according to this method, which indicated the presence of only a mild degree of frontal dysfunction.

Studies of the level of attention in patients with hypertension were performed according to the method of F.E. Rybakov using the technique of counting balls in the sectors that are part of the circle (Fig. 2 A). This made it

\begin{tabular}{|c|c|c|c|}
\hline $\begin{array}{c}\text { MoCA scale } \\
\text { subtests }\end{array}$ & $\begin{array}{c}\text { Maximum } \\
\text { score }\end{array}$ & Average score, M $\pm \mathrm{m} / \mathrm{SD}$ & $\begin{array}{c}\text { Deviation from } \\
\text { maximum } \\
\text { score (\%) }\end{array}$ \\
\hline $\begin{array}{c}\text { Visual-constructive } \\
\text { / executive skills }\end{array}$ & 5 & $3.95 \pm 0,03 / 0,20$ & -21.0 \\
\hline Naming & 3 & $2.67 \pm 0,06 / 0.48$ & -11.0 \\
\hline Warning & 3 & $2.41 \pm 0,07 / 0.55$ & -19.7 \\
\hline $\begin{array}{c}\text { Serial subtraction } \\
\text { Repetition of the } \\
\text { phrase }\end{array}$ & 3 & $1.95 \pm 0,10 / 0.77$ & -35.0 \\
\hline \begin{tabular}{c} 
Speed of speech \\
\hline Abstraction
\end{tabular} & 2 & $1.79 \pm 0.04 / 0.35$ & -10.5 \\
\hline Delayed playback & 5 & $0.89 \pm 0.03 / 0.21$ & -11.0 \\
\hline Orientation & 6 & $1.52 \pm 0,05 / 0.36$ & -24.0 \\
\hline Total score & 30 & $24.37 \pm 0.06 / 0.49$ & -27.0 \\
\hline
\end{tabular}

Table 1 - Indicators of cognitive functions on subtests of the MoCA scale in patients with hypertension with cognitive impairment $(n=60)$

A detailed analysis of the average CF values in patients with hypertension with $\mathrm{Cl}$ on subtests of the MoCA scale (Table 1).

As seen in Table 1, the MoCA test in patients with hypertension indicated that there was a decrease in scores on all subscales compared to healthy controls, but possible to investigate the degree of concentration of the excitatory process in visual and motor analyzers.

As seen in Fig. 2 B, all patients with hypertension with detected $\mathrm{Cl}$ had concentration diversions in the excitatory process of the visual and motor analyzers. Thus, only 2 patients $(1.3 \%)$ performed tasks without errors in 5 
sectors (normal), 28 patients (17.8\%) coped with counting up to 4 sectors, 65 patients (41.4\%) counted 3 sectors, 56 patients $(35.7 \%)$ coped with counting up to two sectors, 6 patients (3.8\%), aged 55 to 65 years, could not complete the task without errors. to perform further due to fatigue and inability to concentrate. The average time of the task in patients of the main group throughout the study exceeded the data of patients in the comparison group by 1.3-1.6 times and healthy individuals, $1.4-1.7$ times $(p<0.001)$.

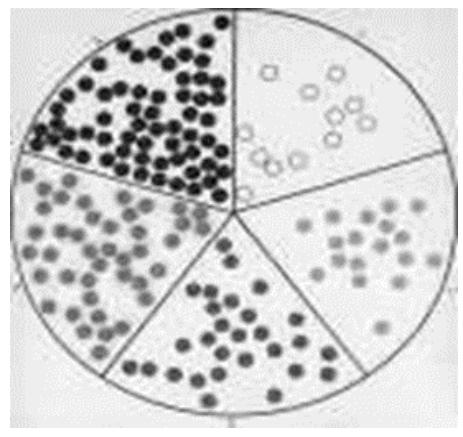

A

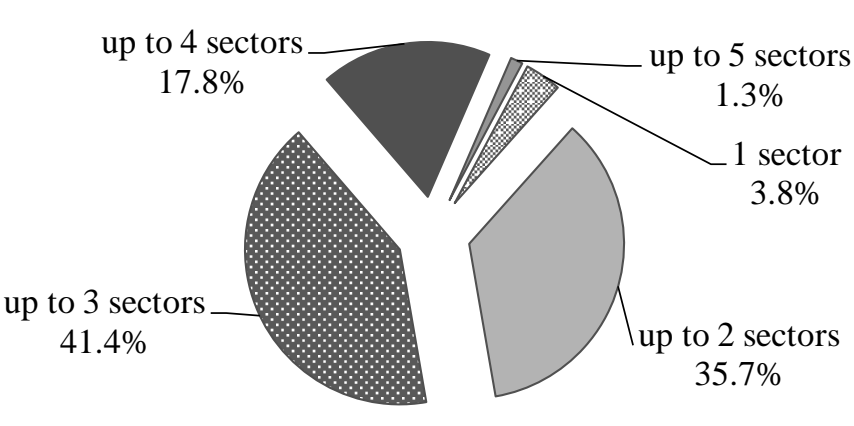

B

Figure 2 - Method of F.E. Rybakova. Scheme of sectors with balls (A). Results study of stability and concentration in patients with hypertension with $\mathrm{Cl}(\mathrm{n}=157)(\mathrm{B})$.

A more in-depth study of the level of attention and speed of sensor motor reactions was carried out according to the method of "Schulte Tables". The obtained data showed a decrease in attention and speed of sensory-motor reactions due to the increase in the time of task performance in the five tables and the presence of errors in the performance of tasks, especially in patients with hypertension and $\mathrm{Cl}$. Such patients were characterized by rapid fatigue, uneven performance of the task, and refusal
Then, based on the results of testing according to Schulte tables, indicators of work efficiency, employability, and mental stability were calculated (Fig. 3).

It was found that in the presence of $\mathrm{Cl}$ in patients with hypertension, performance indicators were significant and mental stability was lower than in patients of the comparison group and healthy individuals (from $p<0.05$ to $p<0.001$ ). This result may be due to first, the

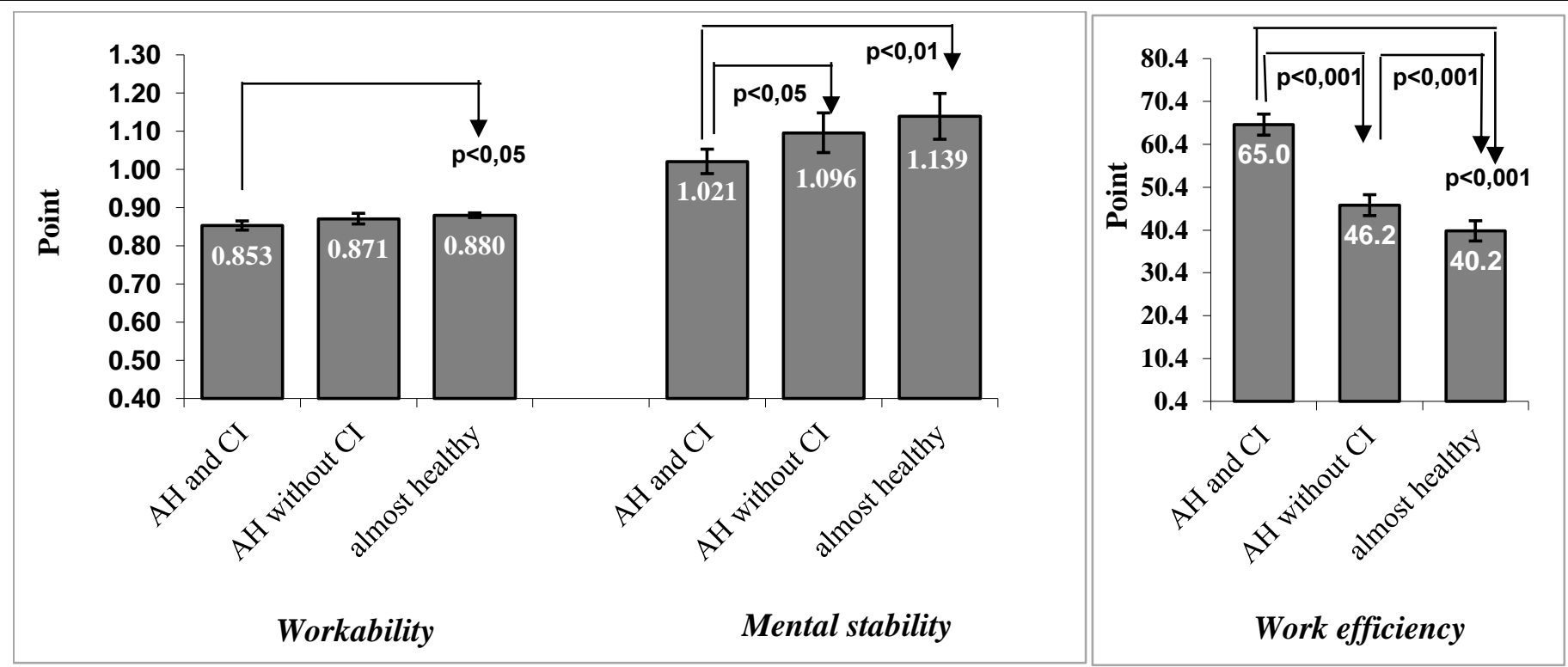

Figure 3 - Average indicators $(\mathrm{M}, 95 \% \mathrm{Cl})$ of work efficiency, employability and mental stability in research groups when tested by the method of Schulte 
peculiarities of the test, and secondly, the excessive diligence of the test participants of this cohort to perform the task against the background of imaginary difficulties. A study of verbal memory according to the method of $A$. Luria found a significant decrease in the volume of direct reproduction, long-term memory and memory efficiency in all examined patients with hypertension and $\mathrm{Cl}$, as compared with patients with hypertension without $\mathrm{Cl}$, and with healthy individuals $(p<0.001)$. Thus, the average number of words reproduced after the first presentation by patients of the main group $(3.80 \pm 0.08)$ was 1.6 times less than in the comparison group $(6.22 \pm 0.26 ; p<0.001)$ and 2.2 times less than relatively healthy individuals (8.29 $\pm 0.45 ; \quad p<0.001)$. The volume of delayed reproduction (long-term memory) in patients with hypertension and $\mathrm{Cl}$ was also 2 and 2.2 times smaller than in groups without $\mathrm{Cl}(\mathrm{p}<0.001)$.

There are significant correlations between the state of CF (assessed by various neuropsychological methods) and the age of patients, disease duration, blood pressure, and/or autonomic index of daily blood pressure monitoring. Thus, with increasing age of the subjects, the assessment of frontal function deteriorated according to the FAB method ( $r s=-0.23 ; p<0.05)$, the degree of concentration of attention according to FE Rybakov ( $r s=$ $0.20 ; p<0.05$ ), visual and constructive skills for MoCA ( $r s=$ $-0.22 ; p<0.05$ ). The long course of hypertension was associated with a decrease in the rate of employment according to the method of Schulte ( $r s=-0.17 ; p<0.05$ ) and the overall score of $\mathrm{Cl}$ on the MoCA test ( $r s=-0.19$; $p<0.05)$ and its subscale: attention ( $r s=-0.29 ; p<0.01)$ and abstraction ( $r s=-0.24 ; p<0.05)$.

Elevated systolic blood pressure affected low levels of verbal memory according to the test of $O$. Luria (from $r s=$ $-0.25 ; p<0.05$ for the second attempt to reproduce words to $r s=-0.43 ; p<0.001$ in delayed playback), reducing the concentration of attention on F.E. Rybakov ( $r s=-0.17$; $\mathrm{p}<0.05$ ) and MoCA subscale score: executive skills ( $r s=-$ $0.19 ; p<0.05)$, naming ( $r s=-0.22 ; p<0.05)$, abstraction ( $r s$ $=-0.24 ; p<0.05)$, delayed recall $(r s=-0.24 ; p<0.05)$. The high vegetative index directly correlated with the increased time for tasks according to Schulte's tables 1 and 2 ( $r s=+0.27 ; p<0.01$ and $r s=+0.23 ; p<0.05)$, as well as with the general indicator of work efficiency ( $r s=+$ $0.17 ; p<0.05)$.

It should be noted that the data obtained on the relationship between the course of hypertension in middle-aged patients and the state of CF are consistent with the results of other studies [13,14], which emphasizes the urgency of timely diagnosis and correction of $\mathrm{Cl}$ in hypertension.

DISCUSSION \& CONCLUSION In patients with controlled, stage II hypertension, $\mathrm{Cl}$ occurred in $32.22 \%$ of cases, which is significantly more common than the presence of relevant complaints. Their characteristics at different levels of higher brain functions correspond to all areas of human cognitive activity, but the most affected are neurodynamic processes (ability to concentrate, speed of psychomotor reactions) and verbal memory, which affect efficiency and success in work, family status. Thus, it is important in the medical rehabilitation of patients with hypertension is not only the control of blood pressure in the corridor of target levels ( $<140$ and $90 \mathrm{~mm} \mathrm{Hg}$ ), but also monitoring and maintaining the mental health of patients.

When conducting screening studies of this cohort of patients, the most informative, sufficient and economical in terms of time and complexity of outpatient practice is the MoCA test. A detailed analysis of the structure of $\mathrm{Cl}$ in patients with hypertension allows achieving compliance with patients and improving their adherence to the doctor's recommendations on lifestyle and medication.

Therefore, further studies of CF in patients with hypertension are promising to determine the risk factors for their development, initial manifestations, and timely correction to maintain quality of life.

\section{REFERENCES:}

1. Impact of Hypertension on Cognitive Function. A Scientific Statement from the American Heart Association; Council on Clinical Cardiology; Council on Cardiovascular Disease in the Young; Council on Cardiovascular and Stroke Nursing; Council on Quality of Care and Outcomes Research; and Stroke Council. J.Hypertension. 2016;68(6). http://hyper.ahajournals.org.

2. Williams B, Mancia G, Spiering W, AgabitiRosei E, Azizi M, Lip GYH, McManus R,Narkiewicz K, Ruschitzka F, Schmieder RE, Shlyakhto E, Tsioufis C, Desormais I; ESC Scientific Document Group. 2018 ESC/ESH Guidelines for themanagement of arterial hypertension. Eur Heart J. 2018 Sep 1;39(33):3021-3104. Doi: 10.1093/eurheartj/ehy339. PubMed PMID: 30165516.

3. Iadecola C, Yaffe K, Biller J, Bratzke LC, Faraci FM, Gorelick PB, Gulati M, Kamel H, Knopman DS, Launer U, Saczynski JS, Seshadri S, Zeki Al Hazzouri A. Impact of hypertension on cognitive function: a scientific statement from the American Heart Association. Hypertension 2016;68: e67. 
4. Coca A, Monteagudo E, Domnech M, Camafort M, Sierra C. Can theTreatmentof Hypertension in the Middle-Aged Prevent Dementia in the Elderly?High Blood Press Cardiovasc Prev. 2016;23(2):97-104.

5. Mancia G., Fagard R., Narkiewicz $K$ et al. ESH/ESC Guidelines for the management of arterial hypertension The Task Force for the management of arterial hypertension of the European Society of Hypertension (ESH) and of the European Society of Cardiology (ESC) Eur. Heart J. 2013;34(28):2159-2219.

6. J. Jiménez-Balado, I. Riba-Llena. Cognitive Impact of Cerebral Small Vessel Disease Changes in Patients with Hypertension. Hypertension. 2019; 73:342-349. https://doi.org/10.1161/HYPERTENSIONAHA.118.120 90

7. Folstein M.F., Folstein S.E., McHugh P.R. Mini-Mental State: a practical guide for grading the mental state of patients for the clinician. J. Psych. Res. 2015; 12:189198.

8. Borson S, Scanlan JM, Watanabe J, Tu SP, Lessig MJ. Simplifying detection of cognitive impairment: comparison of the Mini-Cog and Mini-Mental State Examination in a multiethnic sample. Am GeriatrSoc, 2015; 53(5):871.
9. Milevs'ka-Vovchuk L.S. Comparative characteristics of screening scales for the detection of cognitive impairment. 2015;8(78):41-44.

10.Zaharov V.V. Neuropsychological tests: the need and feasibility. Consiliummedicum. 2011;12(2):98-106.

11.RubynshtejnS.Ja. Experimental methods of pathopsychology and experience in their application in the clinic. Study of verbal memory according to the method of Luria. A practical guide. Moscow; 2007.

12. Armitage P, BerryG, Matthews JNS. (2002) Statistical Methods in Medical Research, 4th ed. Blackwell, Oxford.

13.Elias MF, Wolf PA, D'Agostino RB, Cobb J, White LR. Untreated blood pressure level is inversely related to cognitive functioning: the Framingham study. Am J Epidemiol. 2013; 138:353-364.

14.Gorelick PB, Scuteri A, Black SE, Decarli C, Greenberg SM, ladecola C, Launer $\mathrm{L}$, Laurent S, Lopez OL, Nyenhuis D, Petersen RC, Schneider JA, Tzourio C, Arnett DK, Bennett DA, Chui HC, Higashida RT, Lindquist R, Nilsson PM, Roman GC, Sellke FW, Seshadri S. Vascular contributions to cognitive impairment and dementia. Stroke 2011; 42:26722713. 